2010-05-01

\title{
Speciation and Reactivity of Cisplatin in River Water and Seawater
}

\author{
Curtis, L
}

http://hdl.handle.net/10026.1/3707

$10.1021 /$ es $903620 z$

Environmental Science \&amp; Technology

American Chemical Society (ACS)

All content in PEARL is protected by copyright law. Author manuscripts are made available in accordance with publisher policies. Please cite only the published version using the details provided on the item record or document. In the absence of an open licence (e.g. Creative Commons), permissions for further reuse of content should be sought from the publisher or author. 


\section{Speciation and Reactivity of Cisplatin in River Water and Seawater}

\begin{abstract}
LISA CURTIS, ${ }^{\dagger}$ ANDREW TURNER, ${ }^{*},{ }^{\dagger}$ NITIN VYAS, ${ }^{\neq}$AND GRAHAM SEWELL School of Geography, Earth and Environmental Sciences, University of Plymouth, Drake Circus, Plymouth PLA BAA, United Kingdom, Pharmacy Department, Derriford Hospital, Plymouth PL6 8DH, United Kingdom, and School of Health Professions, Peninsula Allied Health Centre, University of Plymouth, Plymouth PL6 8BH, United Kingdom
\end{abstract}

Received November 30, 2009. Revised manuscript received March 4, 2010. Accepted March 8, 2010.

The adsorption of the cytostatic anticancer drug, cisplatin ( cis$\left.\mathrm{PtCl}_{2}\left(\mathrm{NH}_{3}\right)_{2}\right)$, has been studied after its addition to suspensions of estuarine sediment in river water and seawater. After a $16 \mathrm{~h}$ reaction period, adsorption was significantly greater in river water (sediment-water distribution coefficient, $K_{\mathrm{D}}$, of $400 \mathrm{~mL}$ $\left.\mathrm{g}^{-1}\right)$ than that in seawater $\left(K_{\mathrm{D}} \sim 150 \mathrm{~mL} \mathrm{~g}^{-1}\right)$ because of the ready aquation of cisplatin to the more reactive monoaquacisplatin (cis$\mathrm{PtCl}\left(\mathrm{OH}_{2}\right)\left(\mathrm{NH}_{3}\right)_{2}^{+}$) at low chloride ion concentrations. Adsorption in river water was enhanced $\left(K_{D} \sim 2000 \mathrm{~mL} \mathrm{~g}^{-1}\right)$ by a $24 \mathrm{~h}$ period of preincubation in the aqueous phase in which aquation proceeded further. The effects of $\mathrm{pH}$ on adsorption were relatively small, presumably because protonation-deprotonation of the particle surface was accompanied by near-equivalent shifts in the charge of hydrolysis products of aquated cisplatin. Kinetic experiments revealed a period of slow protracted uptake (up to about $60 \mathrm{~h}$ ), followed by gradual desorption in river water and seawater. Results were interpreted in terms of the formation of monoaquacisplatin, its adsorption to the particle surface, and the subsequent desorption of undefined, unreactive species. Kinetic data were modeled with a sequence of pseudofirst-order reactions and fits were obtained with forward and reverse rate constants for aquation of 1.79 $\times 10^{-5}$ and $1.84 \times 10^{-5} \mathrm{~s}^{-1}$ in river water and $5.50 \times 10^{-6}$ and $5.84 \times 10^{-6} \mathrm{~s}^{-1}$ in seawater, and adsorption and desorption rate constants of $1.75 \times 10^{-5}$ and $0.20 \times 10^{-5} \mathrm{~s}^{-1}$ in river water and $0.98 \times 10^{-5}$ and $2.8 \times 10^{-5} \mathrm{~s}^{-1}$ in seawater. Environmental conditions favoring the retention of cisplatin and its degradation products are low chloride ion concentrations, high turbidities, and long residence or transit times; dispersion of the drug is favored in saline, coastal waters.

\section{Introduction}

Environmental concentrations of platinum are increasing, largely because of its use in the catalytic converters of motor vehicles but also because of the growing demand for Ptbased chemotherapy drugs (1). Although estimates suggest

* Corresponding author phone: +44 1752 584570; fax: +44 1752 584710; e-mail: aturner@plymouth.ac.uk.

+ School of Geography, Earth and Environmental Sciences, University of Plymouth.

${ }^{\ddagger}$ Derriford Hospital.

${ }^{\S}$ Peninsula Allied Health Centre, University of Plymouth. that hospital (and outpatient) waste only constitutes between about $3 \%$ and $12 \%$ of anthropogenic Pt inputs to the environment (2), respectively, this source is of great concern because of the cytotoxicity of Pt in medical applications (3).

Cisplatin (cis- $\mathrm{PtCl}_{2}\left(\mathrm{NH}_{3}\right)_{2}$ ) has found widespread use in chemotherapy because of its affinity for nitrogen donor atoms in the nucleobases of DNA and resulting interference with the mechanism of cell division (4). Cisplatin itself is relatively inert, but in aqueous solutions of low electrolyte concentration chloro ligands are gradually replaced by water in a stepwise process to form the more reactive, aquated species, cis- $\mathrm{PtCl}\left(\mathrm{OH}_{2}\right)\left(\mathrm{NH}_{3}\right)_{2}{ }^{+}$(monoaquacisplatin) and cis- $\mathrm{Pt}\left(\mathrm{OH}_{2}\right)_{2-}$ $\left(\mathrm{NH}_{3}\right)_{2}{ }^{2+}$ (diaquacisplatin) (5)

$$
\text { cis- } \mathrm{PtCl}_{2}\left(\mathrm{NH}_{3}\right)_{2} \underset{k_{-1}}{\stackrel{k_{1}}{\longrightarrow}} \text { cis- } \mathrm{PtCl}\left(\mathrm{OH}_{2}\right)\left(\mathrm{NH}_{3}\right)_{2}^{+}+\mathrm{Cl}^{-}
$$

$$
\text { cis- } \mathrm{PtCl}\left(\mathrm{OH}_{2}\right)\left(\mathrm{NH}_{3}\right)_{2}^{+} \underset{k_{-2}}{\stackrel{k_{2}}{\longrightarrow}} \text { cis- } \mathrm{Pt}\left(\mathrm{OH}_{2}\right)_{2}\left(\mathrm{NH}_{3}\right)_{2}^{2+}+\mathrm{Cl}^{-}
$$

Here, $k_{1}, k_{-1}, k_{2}$, and $k_{-2}$ are the forward and reverse rate constants for the respective reactions, and $K_{1}=k_{1} / k_{-1}$ and $K_{2}=k_{2} / k_{-2}$. On increasing $\mathrm{pH}$, coordinated water molecules participate in aqua-hydroxo equilibria through deprotonation, resulting in the formation of the hydroxo species cis-PtCl$(\mathrm{OH})\left(\mathrm{NH}_{3}\right)_{2}\left(\mathrm{p} K_{\mathrm{a}} \sim 6.5\right)$, cis- $\mathrm{Pt}(\mathrm{OH})\left(\mathrm{OH}_{2}\right)\left(\mathrm{NH}_{3}\right)_{2}{ }^{+}\left(\mathrm{p} K_{\mathrm{a}}\right.$ $\sim 5.5)$, and cis- $\mathrm{Pt}(\mathrm{OH})_{2}\left(\mathrm{NH}_{3}\right)_{2}\left(\mathrm{p} K_{\mathrm{a}} \sim 7.2\right)(6-8)$.

Following administration of the drug, at doses around $100 \mathrm{mg}$ per $\mathrm{m}^{2}$ of body surface, sufficient concentrations of chloride in extracellular fluid $(\sim 100 \mathrm{mM})$ inhibit hydrolysis, and cisplatin is the principal species. Within cells, however, concentrations of chloride an order of magnitude lower ensure that the reactive, aquated forms (but largely monoaquacisplatin) assume dominance (9). Because aqua complexes react with molecules other than DNA, they are also extremely toxic and are classified as carcinogenic to animals and, likely, humans (5).

Because considerable quantities of the drug are eliminated via patients' urine, mainly as cisplatin and monoaquacisplatin, platinum concentrations up to several hundred $\mu \mathrm{g}$ $\mathrm{L}^{-1}$ have been reported in waste waters of oncology wards of large hospitals (10). Given the lengthy plasma elimination half-life of cisplatin (about $130 \mathrm{~h}(11)$ ), however, it is predicted that the majority of the drug and its metabolites are excreted by outpatients into municipal wastewaters (3). Experimental results suggest that while most cisplatin in aquated form is likely to be removed by solids and sludges typical of conventional hospital and municipal treatment plants, significant quantities of the parent drug are conserved (10). Clearly, therefore, cisplatin has the propensity to enter the aquatic environment where its subsequent biogeochemical behavior and impacts are unknown.

From what is understood about the aqueous chemistry of cisplatin and its behavior at the cellular level, it is predicted that in near-neutral fresh water environments the reactive aquated complexes and deprotonated forms thereof will be the predominant species of the drug. Interactions with dissolved and particulate organic matter, and in particular ligands or surface sites containing $\mathrm{N}$ or S (12), are likely to be important. In saline environments, however, the relatively inert and electrically neutral chlorinated form is predicted to be more persistent and, therefore, reactivity with ligands and sediment is limited. To test these assertions, we conducted an experimental investigation into the environmental reactivity of cisplatin. Specifically, we examined the adsorption of the drug added to suspensions of estuarine 
about $0.02 \mu \mathrm{g} \mathrm{L}^{-1}, 0.2 \mu \mathrm{g} \mathrm{L}^{-1}$, and $1.0 \mu \mathrm{g} \mathrm{L}^{-1}$ for river water, seawater, and sediment digests, respectively. Precision, based on relative standard deviations resulting from the analysis of replicate experimental samples, was better than $10 \%$ and $5 \%$ for filtrates of river water and seawater, respectively, and better than $20 \%$ for sediment digests. Analysis of acid rinses of used reactor tubes indicated container adsorption of less than $1.5 \%$ of added Pt in river water and seawater.

Although we report most results on a relative basis, an evaluation of accuracy was ascertained by analysis of aqua regia digests of recycled catalyst pellets (NIST-SRM 2556). Measured Pt concentrations of about $75 \%$ of the certified value are consistent with previous, independent measurements gained by this protocol and reflect the inability of mineral acids to break down the catalytic matrix (15).

\section{Results and Discussion}

Because species of cisplatin were not discriminated analytically, results of the experiments are shown in terms of total $\mathrm{Pt}$ (and on a molar basis) and reflect the net reactivity of a number of chemical forms. Both aqueous and adsorbed Pt concentrations have been employed to calculate the percentage of metal adsorbed to estuarine sediment or the sediment-water distribution coefficient, $K_{\mathrm{D}}\left(\mathrm{mL} \mathrm{g}^{-1}\right)$; the latter is defined as the concentration ratio of Pt adsorbed (on a dry w/w basis) to Pt in solution. Because Pt was detected on filters used in control experiments conducted in river water in which cisplatin was added but sediment was absent (but not in equivalent experiments conducted seawater), it is important to appreciate that coagulation or flocculation may have contributed to the transfer of Pt from solution to the particulate phase in the fresh water end-member. Although this amounted to less than $10 \%$ of the total Pt added, it is not possible to establish the significance of the effect in the presence of estuarine sediment.

Adsorption Isotherms. Figure 1 presents isotherms for the $16 \mathrm{~h}$ adsorption of $\mathrm{Pt}$ in river water and seawater resulting from both the simultaneous addition of the reactants and following a $24 \mathrm{~h}$ period of cisplatin preincubation in the aqueous phase before the addition of sediment. In river water, isotherms are linear and the gradient (or $K_{\mathrm{D}} / 10^{3}$ ) is significantly greater following the period of preincubation. In seawater, adsorption is considerably lower than that in river water. Up to an aqueous Pt concentration of about $15 \mathrm{nM}$, seawater isotherms are coincident; however, subsequent convexity (Freundlich behavior) in the isotherm resulting from preincubation ensures greater adsorption of $\mathrm{Pt}$ when reactants are added simultaneously.

Given that the net surface charge of estuarine particles suspended in river water and seawater is negative (16), adsorption most likely involves interactions between the particle surface and positively charged, hydrolyzed species of aquated cisplatin. Electrostatic interactions have been proposed between aquated cisplatin and phospholipids (17) and drug delivery minerals such as hydroxyapatite (18), while surface complexation with specific binding sites is predicted given the strong interactions between monoaqua cisplatin and certain $\mathrm{N}$ - and S-donor ligands (19). In river water, adsorption is enhanced by a period of preincubation in which further, gradual conversion of cisplatin to more reactive, positively charged species takes place. In seawater, adsorption to estuarine particles is lower than that in river water because the hydrolysis equilibrium in eq 1 is shifted to the left and the greater ionic strength of the matrix reduces the activity of the reactive complexes. As in river water, a period of preincubation is predicted to enhance adsorption of Pt in seawater through the gradual production of the monoaqua species. Given the curvature of the seawater adsorption isotherm under these conditions, however, we suspect that
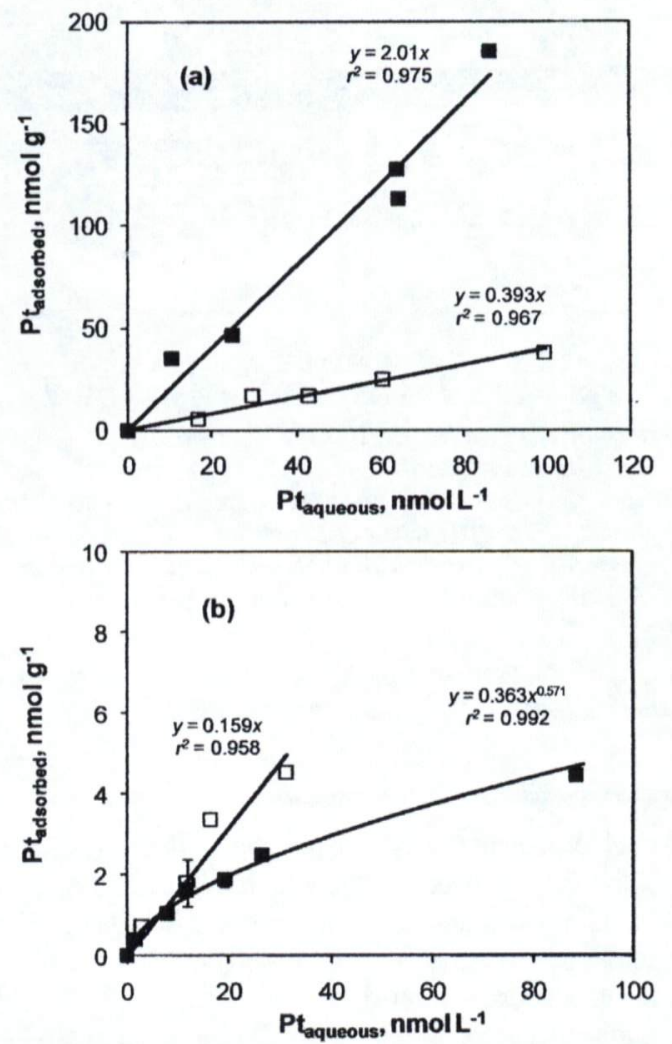

FIGURE 1. Isotherms for cisplatin adsorption to estuarine sediment after $16 \mathrm{~h}$ incubation in (a) river water at $\mathrm{pH} 6.8$ and (b) seawater of salinity 33.3 and $\mathrm{pH}$ 8.2. Isotherms are shown where all reactants were added simultaneously $(\square)$ and where sediment was introduced after cisplatin had been allowed to interact with the aqueous phase for $24 \mathrm{~h}$ ( $\square$ ). Bold lines are best linear or Freundlich fits to the data whose equations are annotated.

competition for adsorption sites from seawater cations occurs, and that this effect is kinetically constrained.

Estuarine Mixing. Figure 2 shows $K_{\mathrm{D}} \mathrm{s}$ for $\mathrm{Pt}$ as a function of salinity, varied by batch mixing of end-members in different proportions, and chloride concentration, varied by addition of different quantities of $\mathrm{NaCl}$ to MQW. In both experiments, a reduction in $K_{\mathrm{D}}$ is observed that was fitted using a simple power law whose coefficients are annotated. Adsorption of Pt to estuarine particles is greater in pure water than in river water and is greater in seawater than in a solution of equivalent chlorinity such that the magnitude of the reduction in $K_{\mathrm{D}}$ is greater across the chloride gradient than the equivalent salinity gradient. Presumably, discrepancies reflect small differences in $\mathrm{pH}$ between the experiments ( 6.8 to 8.2 from river water to seawater compared with about 6.5 in $\mathrm{NaCl}$ solution) and the effects of additional ions, reactants (e.g., dissolved organic matter), and reactions (e.g., flocculation) on the adsorption process across the salinity gradient.

An exponential reduction in $K_{\mathrm{D}}$ during estuarine mixing is characteristic of a variety of trace metals (e.g., $\mathrm{Cd}, \mathrm{Cr}, \mathrm{Ni}$, $\mathrm{Zn}$ ) examined under similar experimental conditions $(20,21)$. In these cases, the effect arises from a nonlinear reduction in the abundance and activity of the free ion and competition for adsorption sites from bivalent seawater cations as salinity increases. With regard to cisplatin, however, the effect is largely attributable to a reduction in the rate and extent of conversion of the electrically neutral parent drug to more reactive, aquated species with increasing chlorinity, as described above. 

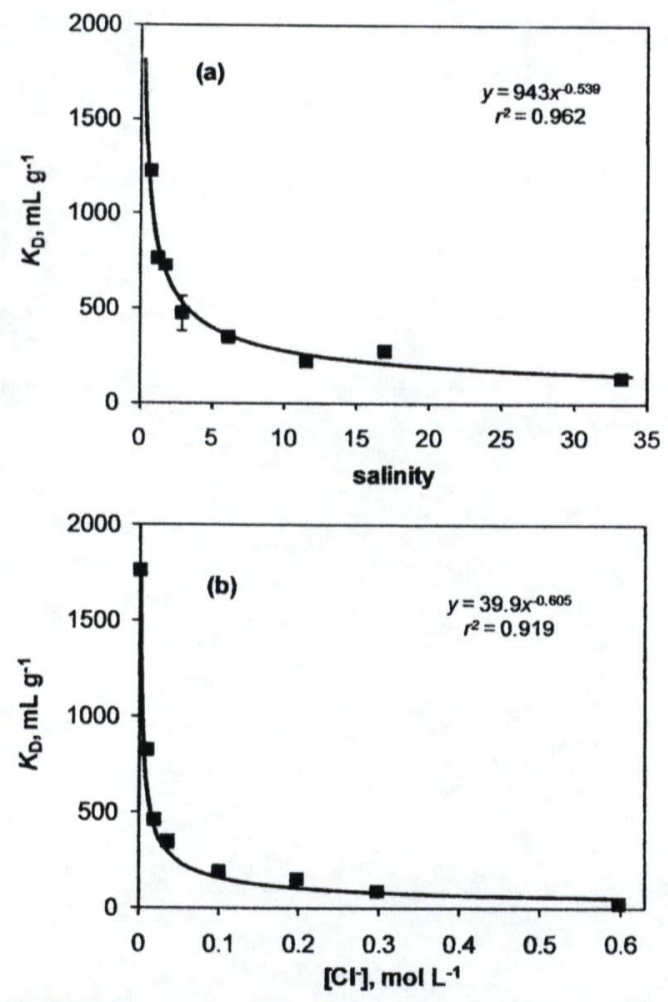

FIGURE 2. Sediment-water distribution coefficients defining cisplatin partitioning after $16 \mathrm{~h}$ (but without a period of preincubation) as a function of (a) salinity (pH 6.8-8.2) and (b) chloride ion concentration (pH 6.5). Bold lines are best power fits to the data, defined by the equations annotated.

Effects of pH. Results of adsorption experiments in which the $\mathrm{pH}$ of river water and seawater was varied are shown in Figure 3. In river water, and regardless of the sequence of reactant addition, adsorption to estuarine particles increases from the lowest value studied to about $\mathrm{pH} \mathrm{5}$, thereafter remaining relatively constant. In seawater, Pt adsorption is lower and displays an increase with increasing $\mathrm{pH}$ that is more pronounced when reactants are introduced simultaneously. A quantitative interpretation of our results is not possible because kinetic constants for cisplatin species (see below) do not exist for the range of conditions studied and we did not measure the surface charge of the fractionated sediment. Qualitatively similar results have, however, been reported for cisplatin adsorption to an alumina stationary phase (19) and an activated sludge (3) and attributed to the net result of two $\mathrm{pH}$-dependent effects, namely, the evolution of surface charge of the solid phase and shifting speciation of cisplatin. Thus, with respect to our results, at low $\mathrm{pH}$, although the hydrolysis equilibria favor the formation of the monoaqua species, adsorption is inhibited because the estuarine particle surface assumes a positive charge. As pH increases, the particle surface becomes more negatively charged but adsorption is offset by the diminishing abundance of the monoaqua species. Significantly, given the narrow range of $\mathrm{pH}$ encountered in seawater and relatively uniform adsorption across the $\mathrm{pH}$ range typical of most rivers (6-9), we may conclude that $\mathrm{pH}$ is not a particularly important variable with respect to particle-water interactions of cisplatin in most surface waters.

Kinetics of Adsorption. Cisplatin reaction kinetics were studied using two approaches, the results of which are presented in Figure 4. The first, continuous approach, conducted in river water and seawater, involved the monitoring of Pt uptake by estuarine sediment in a single reactor, thereby simulating reactions proceeding in a conservative, turbid parcel of water. The second, batch approach, con-
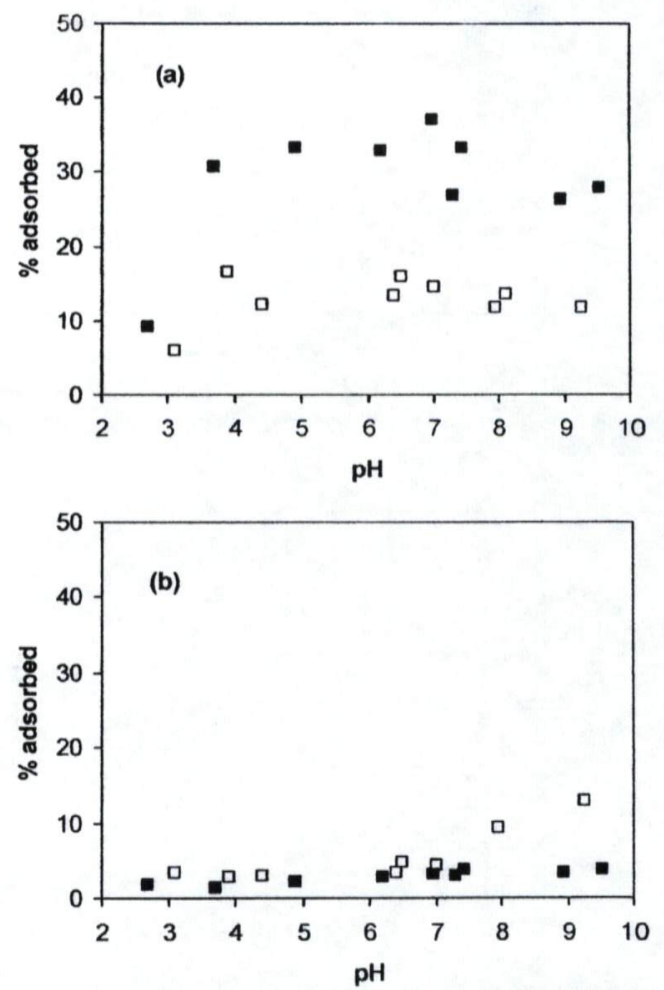

FIGURE 3. Percentage of cisplatin adsorbed to estuarine sediment after $16 \mathrm{~h}$ incubation as a function of "equilibrium" $\mathrm{pH}$ in (a) river water and (b) seawater of salinity 33.3. Results are shown for experiments in which all reactants were added simultaneously ( $\square$ ), and sediment was introduced after cisplatin had been allowed to interact with the aqueous phase for $24 \mathrm{~h}$ ( $\mathrm{E})$.

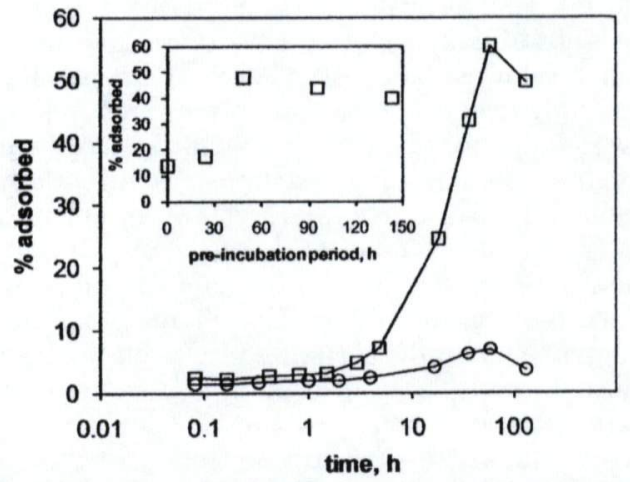

FIGURE 4. Time-dependent adsorption of cisplatin to estuarine sediment suspended in river water at pH $6.8(\square)$ and seawater of salinity 33.3 and $\mathrm{pH} 8.2(\mathrm{O})$. Inset is the $16 \mathrm{~h}$ adsorption of cisplatin to estuarine sediment suspended in river water after different preincubation periods in the aqueous phase.

ducted in river water only, involved equilibrating Pt for different periods of time in individual reactors before the introduction of sediment and a fixed $(16 \mathrm{~h})$ period of adsorption; this approach replicates different transit or residence times in nonturbid water before the addition (e.g., advection or resuspension) of suspended particles. In all cases, adsorption of Pt gradually increased to a maximum after a reaction time or a preincubation period of about $50-60$ $\mathrm{h}$; thereafter, adsorption either decreased (batch approach) or Pt desorbed (continuous approach).

Kinetic Modeling of Pt Speciation and Adsorption. The results presented thus far are qualitatively consistent with observations made on cisplatin speciation and reactivity under physiological conditions, namely, kinetically con- 

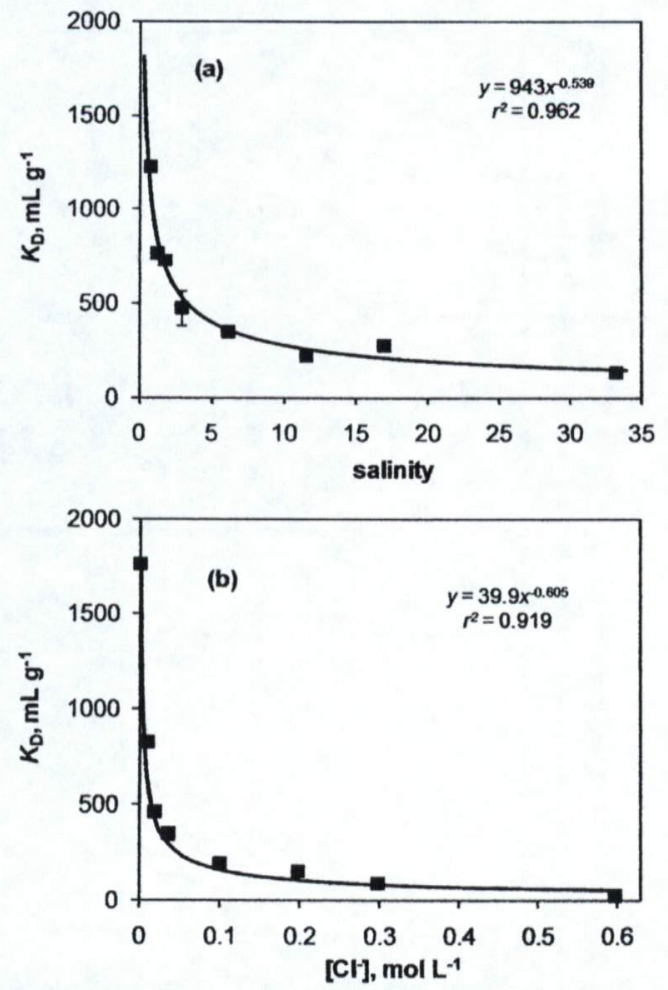

FIGURE 2. Sediment-water distribution coefficients defining cisplatin partitioning after $16 \mathrm{~h}$ (but without a period of preincubation) as a function of (a) salinity (pH 6.8-8.2) and (b) chloride ion concentration ( $\mathrm{pH}$ 6.5). Bold lines are best power fits to the data, defined by the equations annotated.
Effects of pH. Results of adsorption experiments in which the $\mathrm{pH}$ of river water and seawater was varied are shown in Figure 3. In river water, and regardless of the sequence of reactant addition, adsorption to estuarine particles increases from the lowest value studied to about $\mathrm{pH} 5$, thereafter remaining relatively constant. In seawater, Pt adsorption is lower and displays an increase with increasing $\mathrm{pH}$ that is more pronounced when reactants are introduced simultaneously. A quantitative interpretation of our results is not possible because kinetic constants for cisplatin species (see below) do not exist for the range of conditions studied and we did not measure the surface charge of the fractionated sediment. Qualitatively similar results have, however, been reported for cisplatin adsorption to an alumina stationary phase (19) and an activated sludge (3) and attributed to the net result of two $\mathrm{pH}$-dependent effects, namely, the evolution of surface charge of the solid phase and shifting speciation of cisplatin. Thus, with respect to our results, at low $\mathrm{pH}$, although the hydrolysis equilibria favor the formation of the monoaqua species, adsorption is inhibited because the estuarine particle surface assumes a positive charge. As pH increases, the particle surface becomes more negatively charged but adsorption is offset by the diminishing abundance of the monoaqua species. Significantly, given the narrow range of $\mathrm{pH}$ encountered in seawater and relatively uniform adsorption across the $\mathrm{pH}$ range typical of most rivers $(6-9)$, we may conclude that $\mathrm{pH}$ is not a particularly important variable with respect to particle-water interactions of cisplatin in most surface waters.

Kinetics of Adsorption. Cisplatin reaction kinetics were studied using two approaches, the results of which are presented in Figure 4. The first, continuous approach, conducted in river water and seawater, involved the monitoring of Pt uptake by estuarine sediment in a single reactor, thereby simulating reactions proceeding in a conservative, turbid parcel of water. The second, batch approach, con-
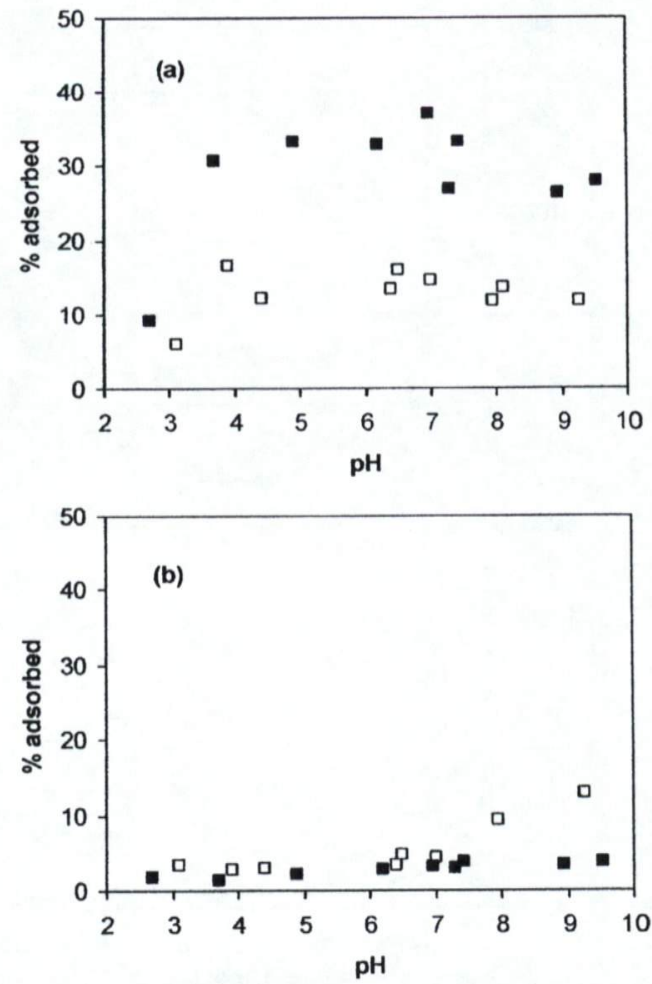

FGURE 3. Percentage of cisplatin adsorbed to estuarine sediment after $16 \mathrm{~h}$ incubation as a function of "equilibrium" $\mathrm{pH}$ in (a) river water and (b) seawater of salinity 33.3. Results are shown for experiments in which all reactants were added simultaneously ( $\square$ ), and sediment was introduced after cisplatin had been allowed to interact with the aqueous phase for $24 \mathrm{~h}(\mathbf{})$.

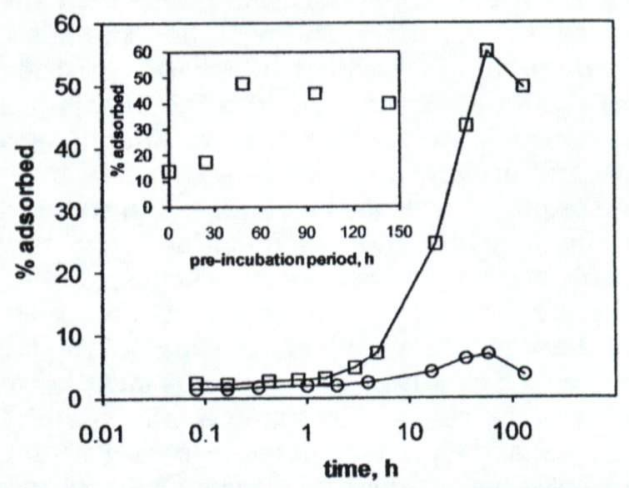

FIGURE 4. Time-dependent adsorption of cisplatin to estuarine sediment suspended in river water at pH 6.8 ( $\square$ ) and seawater of salinity 33.3 and $\mathrm{pH} 8.2(\mathrm{O})$. Inset is the $16 \mathrm{~h}$ adsorption of cisplatin to estuarine sediment suspended in river water after different preincubation periods in the aqueous phase.

ducted in river water only, involved equilibrating Pt for different periods of time in individual reactors before the introduction of sediment and a fixed $(16 \mathrm{~h})$ period of adsorption; this approach replicates different transit or residence times in nonturbid water before the addition (e.g., advection or resuspension) of suspended particles. In all cases, adsorption of Pt gradually increased to a maximum after a reaction time or a preincubation period of about $50-60$ $\mathrm{h}$; thereafter, adsorption either decreased (batch approach) or Pt desorbed (continuous approach).

Kinetic Modeling of Pt Speciation and Adsorption. The results presented thus far are qualitatively consistent with observations made on cisplatin speciation and reactivity under physiological conditions, namely, kinetically con- 
trolled, nonenzymatic transformations that are dependent on chloride ion concentration (5). Because physiological pH and chloride ion concentration are similar to the $\mathrm{pH}$ and chlorinity of the river water employed in the experiments, we have adopted rate constants reported in the pharmacological literature to model Pt speciation and simulate its adsorption in the fresh water end-member.

Because the diaqua complex is not believed to be significant in aqueous solutions of cisplatin or under physiological conditions $(7,9,19)$, monoaquacisplatin was assumed to be the only form of Pt able to adsorb to the estuarine sediment surface (the reactivity of the $\mathrm{Pt}-\mathrm{OH}_{2}$ bond is far greater than that of the $\mathrm{Pt}-\mathrm{OH}$ and $\mathrm{Pt}-\mathrm{Cl}$ bonds; 5). It is important to appreciate, however, that less reactive, deprotonated derivatives of both diaquacisplatin (e.g., cis$\left.\mathrm{Pt}(\mathrm{OH})_{2}\left(\mathrm{NH}_{3}\right)_{2}\right)$ and monoaquacisplatin (cis- $\mathrm{PtCl}(\mathrm{OH})\left(\mathrm{NH}_{3}\right)_{2}$ ) may exist at the $\mathrm{pH}$ of the experiments. The eventual decline in adsorbed $\mathrm{Pt}$ that was persistently observed in the experiments was modeled as desorption of one or more undefined and unreactive species. Analytically irresolvable species have been reported in aqueous solution (22), and here we assume they form by some chemical or biological process at the estuarine particle surface. Because quantities of $\mathrm{Cl}^{-}$created or consumed are small relative to the concentration of $\mathrm{Cl}^{-}$ in river water, all reactions are pseudofirst-order and their sequence is thus

$$
\begin{aligned}
c i s-\mathrm{PtCl}_{2}\left(\mathrm{NH}_{3}\right)_{2 \text { (aq) }} \underset{k_{-1}}{\stackrel{k_{1}}{\longrightarrow}} \text { cis- } \mathrm{PtCl}\left(\mathrm{OH}_{2}\right)\left(\mathrm{NH}_{3}\right)_{2(\mathrm{aq})}^{+} \stackrel{\stackrel{k_{\text {ads }}}{\longrightarrow}}{ } \\
c i s-\operatorname{PtCl}\left(\mathrm{OH}_{2}\right)\left(\mathrm{NH}_{3}\right)_{2 \text { (ads) }}^{+} \stackrel{k_{\text {des }}}{\longrightarrow} \mathrm{PtX}_{(\mathrm{aq})}
\end{aligned}
$$

where $k_{\text {ads }}$ and $k_{\text {des }}$ are adsorption and desorption rate constants, respectively, and PtX represents undefined degradation products released from the particle surface.

Aqueous speciation in river water, shown in Figure 5, was computed using ModelMaker v4 (Cherwell Scientific) and forward and reverse rate constants for the first aquation step at $25^{\circ} \mathrm{C}$ of $1.79 \times 10^{-5}$ and $1.84 \times 10^{-5} \mathrm{~s}^{-1}$, respectively (22). Adsorption and desorption rate constants of $1.75 \times 10^{-5}$ and $2.00 \times 10^{-6} \mathrm{~s}^{-1}$, respectively, were then estimated by fitting experimental adsorption data using the Runge-Kutta numerical optimization algorithm in the software. Excellent agreement between observed and computed adsorption is attained in the long term $(>20 \mathrm{~h})$. However, the model was not able to reproduce the precise extent of adsorption at the beginning of the time course, presumably because initial interactions of Pt with the particle surface are extremely rapid.

Because rate constants for cisplatin conversion do not exist for seawater or solutions of equivalent chlorinity, we fitted adsorption data in seawater (salinity $=33.3$ ) iteratively using ModelMaker and the same sequence of pseudofirstorder reactions. Modeled results, shown in Figure 5, required rate constants for $k_{1}, k_{-1}, k_{\text {ads }}$, and $k_{\text {des }}$ of $5.50 \times 10^{-6}, 5.84$ $\times 10^{-6}, 0.98 \times 10^{-5}$, and $2.80 \times 10^{-5} \mathrm{~s}^{-1}$, respectively. As above, excellent agreement was attained in the long term, but the model underestimated the rate of initial adsorption. Thus, relative to river water, formation of the monoaqua complex proceeds more slowly in seawater because the hydrolysis equilibrium is shifted to the left. Adsorption is also suppressed in seawater because the ion activity of the monoaqua species is reduced, but desorption appears to be accelerated, likely due to competition for adsorption sites from seawater cations.

Environmental Implications. To our knowledge, this is the first systematic study of the reactivity of any Pt-based anticancer drug in natural waters. Concentrations of cisplatin employed in the experiments are sufficiently low relative to those of other reactants (with the possible exception of specific, organic ligands; see below) to conclude that the
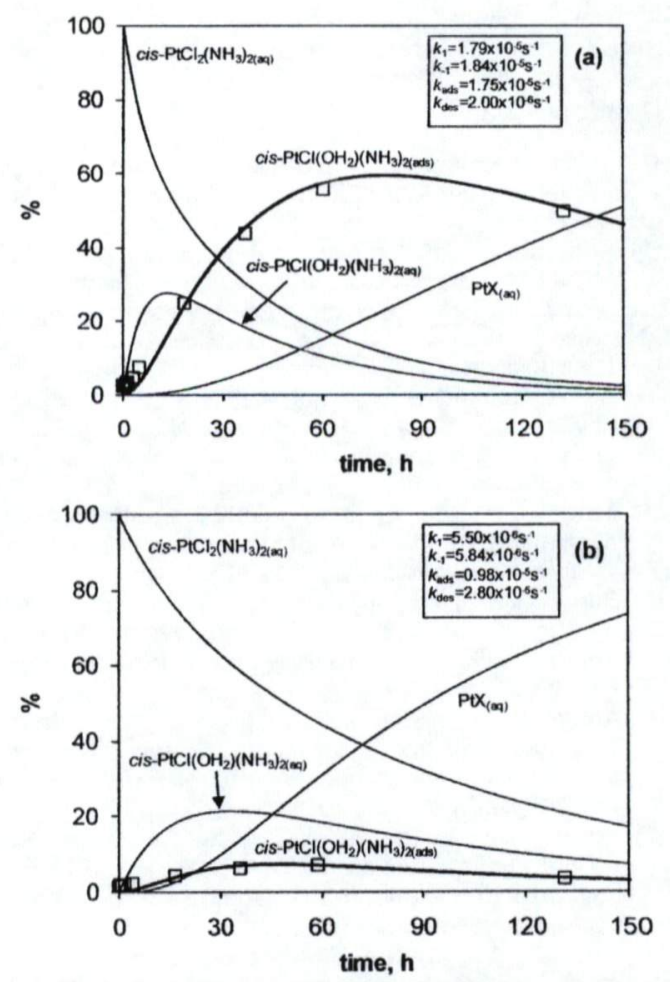

FIGURE 5. Speciation of cisplatin in (a) river water at $\mathrm{pH} 6.8$ and (b) seawater of salinity 33.3 and $\mathrm{pH} 8.2$ as a function of time. Aqueous species were calculated using ModelMaker v4 and the forward and reverse aquation rate constants indicated. Adsorbed Pt was fitted to experimental data ( $\square$ ) using adsorption and desorption constants derived using the RungeKutta numerical optimization algorithm in the software and as shown.

principal findings are applicable at environmentally realistic concentrations of the drug (although this itself is unknown). Our results are, therefore, critical to understanding the behavior and predicting the fate of this cytostatic chemical in rivers, estuaries, and coastal waters. Interactions of cisplatin with sediment in the environment are highly sensitive to chloride ion concentration and are kinetically constrained; variations in $\mathrm{pH}$ appear to be of less significance because the accompanying change in the surface charge of particles is countered by the shift in the proportion of reactive aqueous species. The role of organic matter is less clear, but theoretical considerations, differences in results of experiments conducted in MQW and river water, and evidence of cisplatin flocculation in the latter suggest that complexation with specific (e.g., $\mathrm{N}$ - and S-donor) ligands is likely.

Environmental conditions that favor the retention of cisplatin are those that favor the formation of the (mono-) aquated species and its propensity to adsorb, that is, turbid waters of low chlorinity and long residence or transit time. Equivalent, low turbidity conditions, however, are predicted to incur greatest exposure of the cytotoxic species to aquatic life. Conditions that favor the dispersal of cisplatin are those that inhibit the formation of the aquated species and its adsorption, namely, rapidly flushed environments of high chlorinity and low turbidity. The subsequent biogeochemical behavior and effects of aqueous and adsorbed cisplatin in rivers, estuaries, and coastal waters (e.g., response to reducing conditions, remobilization, bioaccessibility, and toxicity) are unknown and require investigation.

\section{Acknowledgments}

We thank Andy Fisher, Rob Clough (both UoP), and Pritesh Patel (Laverstoke Park, Basingstoke) for assistance with the 
Pt analysis. We are grateful to Prof. Geoff Millward (UoP) for useful comments about kinetic modeling.

\section{Literature Cited}

(1) Ravindra, K.; Bencs, L.; van Grieken, R. Platinum group elements in the environment and their health risk. Sci. Total Environ. 2004, 318, 1-43.

(2) Kümmerer, K.; Helmers, E.; Hubner, P.; Mascart, G.; Milandri, M.; Reinthaler, F.; Zwakenberg, M. European hospitals as a source of platinum in the environment in comparison with other sources. Sci. Total Environ. 1999, 225, 155-165.

(3) Lenz, K.; Hann, S.; Koellensperger, G.; Stefanka, Z.; Stingedeer, G.; Weiseenbacher, N.; Mahnik, N. S.; Fuerhacker, M. Presence of cancerostatic platinum compounds in hospital wastewater and possible elimination by adsorption to activated sludge. Sci. Total Environ. 2005, 345, 141-152.

(4) Muggia, F. Platinum compounds 30 years after the introduction of cisplatin: Implications for the treatment of ovarian cancer. Gynecol. Oncol. 2009, 112, 275-281.

(5) Berners-Price, S. J.; Appleton, T. G. The Chemistry of Cisplatin in Aqueous Solution. In Platinum-Based Drugs in Cancer Therapy, Kell, L. R., Farrell., N., Eds.; Humana Press: Totowa, NJ, 2000; pp 3-35.

(6) Appleton, T. G.; Hall, J. R.; Ralph, S. F.; Thompson, C. S. M NMR study of acid-base equilibria and other reactions of ammineplatinum complexes with aqua and hydroxo ligands. Inorg. Chem. 1989, 28, 1989-1993.

(7) Miller, S. E.; House, D. A. The hydrolysis products of cisdichlorodiammineplatinum(II) 2. The kinetics of formation and anation of the cis-diamminedi(aqua)platinum(II) cation. Inorg. Chim. Acta 1989, 166, 189-197.

(8) Orton, D. M.; Gretton, V. A.; Green, M. Acidity constants for cis-diaquadiammineplatinum(II), the aquated form of cisplatin. Inorg. Chim. Acta 1993, 204, 265-266.

(9) Jennerwein, M.; Andrews, P. A. Effect of intracellular chloride on the cellular pharmacodynamics of cis-diamminedichloroplatinum(II). Drug Metab. Dispos. 1995, 23, 178-184.

(10) Lenz, K.; Koellensperger, G.; Hann, S.; Weiseenbacher, N.; Mahnik, S. N.; Fuerhacker, M. Fate of cancerostatic platinum compounds in biological wastewater treatment of hospital effluents. Chemosphere 2007, 69, 1765-1774.

(11) Vermorken, V. B.; van der Vijgh, W. J.; Klein, I.; Hart, A. A.; Gall, H. E. E.; Pinedo, H. M. Pharmacodynamics of free and total platinum species after short-term infusion of cisplatin. Cancer Treat. Rep. 1984, 68, 503-513.
(12) Fireman-Shoresh, S.; Hüsing, N.; Avnir, D. Adsorption/desorption characteristics of $c i s$-platin on mercapto-silyated silica surfaces. Langmuir 2001, 17, 5958-5963.

(13) Turner, A.; Millward, G. E.; Le Roux, S. M. Significance of oxides and particulate organic matter in controlling trace metals partitioning in a contaminated estuary. Mar. Chem. 2004, 88, 179-192.

(14) Turner, A.; Crussell, M.; Millward, G. E.; Cobelo-Garcia, A.; Fisher, A. S. Adsorption kinetics of platinum group elements in river water. Environ. Sci. Technol. 2006, 40, 1524-1531.

(15) Turner, A.; Price, S. Bioaccessibility of platinum group elements in automotive catalytic converter particulates. Environ. Sci. Technol. 2008, 42, 9443-9448.

(16) Beckett, R.; Le, N. P. The role of organic matter and ionic composition in determining the surface charge of suspended particles in natural waters. Colloids Surf. 1990, 44, 35-49.

(17) Speelmans, G.; Sips, W. H. H. M.; Grisel, R. J. H.; Staffhorst, R.W.H. M.Fichtinger-Schepman, A. M. J.; Reedijk, J.; de Kruijff, B. The interaction of the anti-cancer drug cisplatin with phospholipids is specific for negatively charged phospholipids and takes place at low chloride ion concentration. Biochim. Biophys. Acta 1996, 1283, 60-66.

(18) Barroug, A.; Glimcher, M. J. Hydroxyapatite crystals as a loca delivery system for cisplatin: Adsorption and release of cisplatin in vitro. J. Orthop. Res. 2002, 20, 274-280.

(19) Shearan, P.; Alvarez, J. M. F.; Zayed, N.; Smyth, M. R. Highperformance liquid chromatographic separation of cisplatin and its hydrolysis products on alumina and application to studies of their interaction with cysteine. Biomed. Chromatogr. 1990, 4, $78-82$.

(20) Turner, A.; Nimmo, M.; Thuresson, K.A. Speciation and sorptive behaviour of nickel in an organic-rich estuary (Beaulieu, UK). Mar. Chem. 1998, 63, 105-118.

(21) Turner, A. Trace metal partitioning in estuaries: Importance of salinity and particle concentration. Mar. Chem. 1996, 54, 2739.

(22) Hann, S.; Koellensperger, G.; Stefanka, Zs.; Stingeder, G.; Fürhacker, M.; Buchberger, W.; Mader, R. M. Application of HPLC-ICP-MS to speciation of cisplatin and its degradation products in water containing different chloride concentrations and in human urine. J. Anal. At. Spectrom 2003, 18, 13911395. 